\title{
Helper virus-free gutless adenovirus (HF-GLAd): a new platform for gene therapy
}

\author{
Jida Liu \& Dai-Wu Seol* \\ College of Pharmacy, Chung-Ang University, Seoul 06974, Korea
}

Gene therapy is emerging as a treatment option for inherited genetic diseases. The success of this treatment approach greatly depends upon gene delivery vectors. Researchers have attempted to harness the potential of viral vectors for gene therapy applications over many decades. Among the viral vectors available, gutless adenovirus (GLAd) has been recognized as one of the most promising vectors for in vivo gene delivery. GLAd is constructed by deleting all the viral genes from an adenovirus. Owing to this structural feature, the production of GLAd requires a helper that supplies viral proteins in trans. Conventionally, the helper is an adenovirus. Although the helper adenovirus efficiently provides helper functions, it remains as an unavoidable contaminant and also generates replicationcompetent adenovirus (RCA) during the production of GLAd. These two undesirable contaminants have raised safety concems and hindered the clinical applications of GLAd. Recently, we developed helper virus-free gutless adenovirus (HF-GLAd), a new version of GLAd, which is produced by a helper plasmid instead of a helper adenovirus. Utilization of this helper plasmid eliminated the helper adenovirus and RCA contamination in the production of GLAd. HF-GLAd, devoid of helper adenovirus and RCA contaminants, will facilitate its clinical applications. In this review, we discuss the characteristics of adenoviruses, the evolution and production of adenoviral vectors, and the unique features of HF-GLAd as a new platform for gene therapy. Furthermore, we highlight the potential applications of HF-GLAd as a gene delivery vector for the treatment of various inherited genetic diseases. [BMB Reports 2020; 53(11): 565-575]

\section{INTRODUCTION}

The first approved clinical application of gene therapy took

${ }^{*}$ Corresponding author. Tel: +82-2-820-5594; Fax: +82-2-816-7338; E-mail: seold@cau.ac.kr

https://doi.org/10.5483/BMBRep.2020.53.11.185

Received 18 August 2020

Keywords: Adenovirus, Gene therapy, Genetic disease, GLAd, Gutless adenovirus, Helper plasmid, Helper virus, HF-GLAd, RCA place in the US almost three decades ago (1-3). Since then, advances in gene therapy have led to new therapeutic opportunities for once untreatable inherited genetic diseases. To date, three in vivo gene therapy products-Glybera (4), Luxturna (5), and Zolgensma (6) - for the treatment of inherited genetic diseases have been approved in Europe and the US, and more products are expected to be available soon.

The fundamental principle of gene therapy is to deliver a functional copy (a therapeutic transgene) of the mutant gene to physiologically relevant target tissues or organs of the patient to compensate for the mutant gene. A therapeutic transgene can be delivered into the patient's body via two methods: (1) an ex vivo approach, in which the patient's cells are first modified by therapeutic transgenes outside the body and then transplanted back into the patient's body; (2) an in vivo approach, in which therapeutic transgenes are directly delivered into the patient's body and cells are modified in situ. In either method, a vehicle called 'vector' is needed to deliver the therapeutic transgenes.

Safety is the highest priority in every therapeutic intervention. The vectors for gene therapy are no exception, and thus, the safety of the gene delivery vectors should be carefully and continuously monitored. Additionally, the gene delivery vectors should be able to sustain high-level and persistent transgene expression in host organisms to achieve therapeutic efficacy of the transgenes delivered.

Among all the currently available vectors for in vivo gene delivery, gutless adenovirus (GLAd) has been recognized as one of the most promising vectors (7). GLAd does not integrate into the host genome, and instead remains as an episome in the nucleus, which eliminates concerns related to insertional mutagenesis and germline transmission. GLAd also exhibits a broad tropism and high efficiency in gene delivery. Importantly, GLAd induces negligible immune responses in host organisms, enabling high-level and persistent transgene expression in many types of tissues. Furthermore, GLAd can accommodate transgenes of up to $36 \mathrm{~kb}$, which allows the delivery of a large transgene or multiple transgenes. These advantages of GLAd as a gene delivery vector have drawn the tremendous attention of researchers toward gene therapy applications.

However, despite the obvious benefits, the currently available GLAd has a notable drawback: contamination with adenovirus and RCA in its final product. Safety concerns raised by these

ISSN: 1976-670X (electronic edition)

Copyright (c) 2020 by the The Korean Society for Biochemistry and Molecular Biology

(c) This is an open-access article distributed under the terms of the Creative Commons Attribution Non-Commercial License (http://creativecommons.org/licenses/by-nc/4.0) which permits unrestricted non-commercial use, distribution, and reproduction in any medium, provided the original work is properly cited. 
contaminants have hindered its clinical applications. Recently, we successfully developed helper virus-free gutless adenovirus (HF-GLAd), a new version of GLAd, which is produced by a helper plasmid. HF-GLAd, free of helper adenovirus and RCA contaminants, will facilitate its clinical applications.

In this review, we discuss the characteristics of adenovirus, the evolution of adenoviral gene delivery vectors, and the host immune responses against adenoviral vectors. Moreover, we highlight the unique features of HF-GLAd as a new platform for in vivo gene therapy in various inherited genetic diseases and discuss the possible applications of HF-GLAd-based gene therapy for other diseases.

\section{CHARACTERISTICS OF ADENOVIRUS}

The first adenovirus was isolated from the tissue culture of human adenoids in 1953 and characterized by Rowe et al. (8) and Hilleman et al. (9). To date, 57 human adenoviruses (HAd-1 to HAd-57) have been identified and classified into seven serotypes (HAd-A to HAd-G) (10). All of these adenoviruses exhibit the same overall architecture. They measure 90-100 nm in diameter and are non-enveloped viruses containing a linear, non-segmented double-strand DNA genome wrapped in an icosahedral capsid.

The capsid of adenovirus is composed of 292 capsomeres with 20 triangular facets and 12 vertices. These capsomeres consist mainly of 240 hexons (trimer of protein II) on the facet and 12 pentons on the vertices of the capsid (Fig. 1A). The penton unit consists of a penton base (pentamer of protein III) anchored in the capsid and a projecting fiber (trimer of protein $\mathrm{VI}$ ) with a knob at its distal end (Fig. 1B). Besides, several other minor structural proteins, including IIIa, VIII, IX, vIII, terminal protein (TP) and $\mathrm{V}$, are located on the internal and external surface of the capsid (Fig. 1B).

The capsid contains a relatively large adenoviral genome (30-40 kb). For example, human adenovirus type 5 (HAd5), a member of HAd serotype $\mathrm{C}$, contains an approximately $36 \mathrm{~kb}$ genome. The HAd5 genome carries an inverted terminal repeat (ITR) ( $100 \mathrm{bp})$ at both ends, each of which is covalently attached to a TP at the $5^{\prime}$-terminus of each DNA strand (Fig. 1C). The ITR sequence on the left end of the adenoviral genome is followed by the $\psi$ packaging signal that controls the encapsidation of the viral genome (Fig. 1C). In addition to the ITRs and the $\psi$ packaging signal, there are 38 viral genes organized in 17 transcriptional units classified into early, intermediate, and late categories (Fig. 1C). The early (E) transcriptional units (E1-E4) encode proteins that regulate viral gene transcription, viral DNA replication, and the suppression of host immune responses against adenoviral infection. The intermediate transcriptional units code for two proteins, IX and IVa2. The late (L) transcriptional units (L1-L5) encode the structural proteins of adenovirus.
A
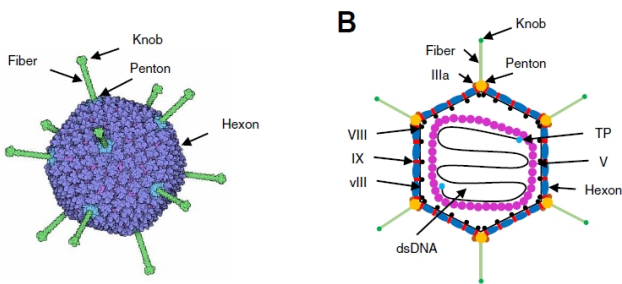

C

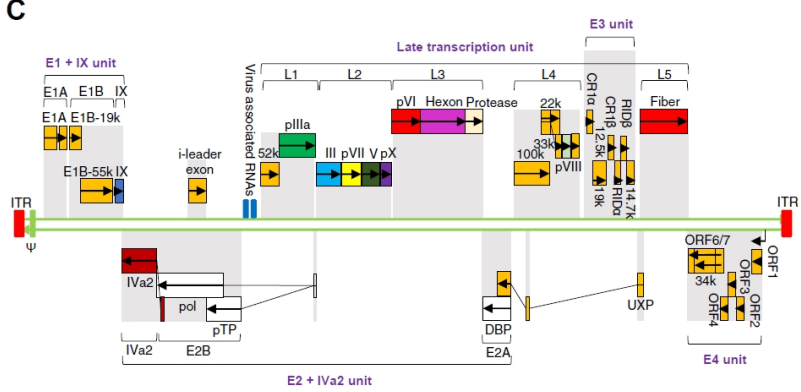

Fig. 1. The capsid and genomic structure of adenovirus. (A) The capsid of adenovirus. The icosahedral capsid of adenovirus is composed of 3 major types of proteins: 12 knobbed fibers, 12 pentons, and 240 hexons. (B) Cross-section through the capsid of adenovirus. The adenovirus is $90-100 \mathrm{~nm}$ in diameter. Several types of minor proteins, such as IIla, VIII, IX, vIII, bind in the grooves between the major proteins, hexons, and pentons. The viral genome DNA binds covalently to the terminal protein (TP) at $5^{\prime}$ ends and is wrapped in nucleocapsid consisting of histone-like proteins, such as protein V. (C) The genomic structure of HAd5. The HAd5 genome is a linear, non-segmented, double-stranded DNA molecule with a length of $36 \mathrm{~kb}$. The 38 viral protein-coding genes are organized in 17 transcriptional units, categorized into early units (E1-E4), intermediate units, and late units (L1-L5) in both directions. The early transcriptional units encode proteins that are involved in the initiation of viral DNA replication (E1), the regulation of viral transcription (E2 and E4), and the suppression of host responses to adenoviral infection (E3). The intermediate transcriptional units encode two proteins, IX and IVa2. The late transcriptional units (L1-L5) encode the components of viral capsid.

\section{EVOLUTION OF ADENOVIRAL GENE DELIVERY VECTORS}

Most adenoviral vectors are derived from HAd5, and classified into two categories: replication-competent and replication-defective. The replication-competent adenovirus (RCA) has been developed typically as a tool for anti-cancer therapy. Since RCA can replicate by itself and is strongly immunogenic, it plays a role in the lysis of infected and adjacent tumor cells when injected into tumor tissues. In contrast, the replicationdefective adenovirus has been primarily developed as a gene delivery vector, following the modifications by deleting viral genes partially or entirely to reduce or eliminate the expression of viral proteins. These modifications have been shown to attenuate the host immune responses. Based on the modifica- 
tions, several generations of adenoviral vectors have been constructed as follows.

\section{The first- and second-generation adenoviral vectors}

The first-generation adenovirus (FGAd) was constructed by deleting the $\mathrm{E} 1$ region (from nucleotide 400 to 3500 ) and the E3 region from the adenoviral genome (Fig. 2). The E1 region encodes proteins essential for the expression of other early and late genes, and thus, is crucial in initiating the life cycle of adenovirus (11). The E3 region encodes proteins that protect adenovirus from the host antiviral immune responses (12). Since these E3 proteins are dispensable for adenovirus production, the E3 region is generally deleted in the FGAd to increase its cargo capacity for the transgene.

Due to the deletion of the E1 region, FGAd cannot replicate by itself. Therefore, the production of FGAd requires packaging cell lines that express E1 proteins in trans to compensate for the lack of E1 region. The cell line most commonly used for FGAd production is the human embryonic kidney (HEK) 293 (13) that contains an insertion of the E1 region (from nucleotide 1 to 4334 ) at 19q13.2 in its genome (14). Unfortunately, utilization of this cell line has a potential drawback, RCA generation, resulting from homologous recombination between the FGAd genome and this cell line (15). Although the occurrence of RCA is low during the initial passages of FGAd (16), the RCA is rapidly amplified at higher passages, leading to serious safety concerns in clinical applications (17). According to the FDA guidelines, there should be less than 1 RCA in $3 \times$ $10^{10}$ viral particles (vp) (18). Despite the safety concerns associated with RCA, HEK293 is still the most frequently used cell line for FGAd production. An alternative cell line, PER.C6 (19), has been developed to limit RCA generation; however, this cell line has not been widely used due to strict licensing.

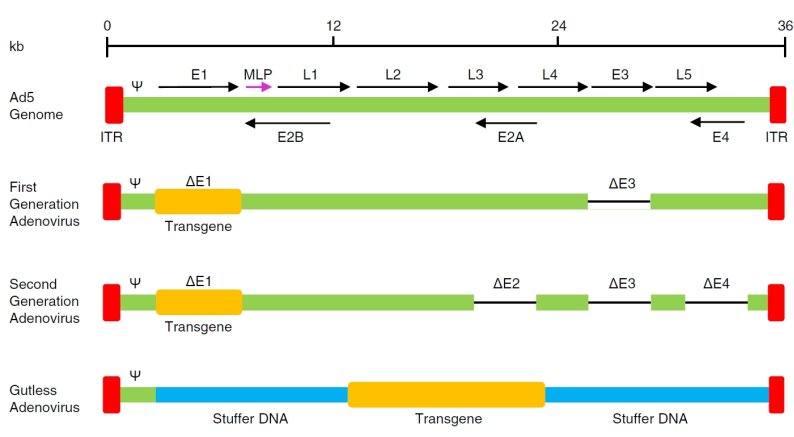

Fig. 2. Three generations of adenoviral vectors. The first-generation adenovirus (FGAd) is constructed by removing the E1 and E3 regions from the adenoviral genome. The second-generation adenovirus (SGAd) is generated via further deletions in the E2 and E4 regions. The third-generation adenovirus, referred to as gutless adenovirus (GLAd), is constructed by deleting all the viral protein-coding genes, leaving only the ITRs and the $\psi$ packaging signal in its genome backbone.
Even though FGAd is devoid of the E1 region, the E1A-like factors present in many cell types can still induce the expression of other adenoviral proteins in transduced host cells (20), eliciting strong host immune responses and resulting in transient transgene expression and chronic toxicity (21). Therefore, FGAd has been recognized as a suitable platform for the delivery of transgenes in anti-cancer therapy (22) rather than a platform for delivering therapeutic transgenes to treat inherited genetic diseases, which requires high-level and persistent transgene expression.

In an attempt to attenuate the host immune responses against adenoviral proteins, the second-generation adenovirus (SGAd) was generated via additional deletions of the E2 and E4 regions (Fig. 2). The E2 region encodes three proteins related to the replication of viral DNA (23), including DNAbinding protein (DBP), terminal protein (TP), and DNA polymerase. The $\mathrm{E} 4$ region codes for control proteins that regulate the transcription of adenoviral DNA (24). These deletions significantly reduce the synthesis of adenoviral proteins. Nonetheless, SGAd still induces host immune responses due to the proteins expressed from the residual adenoviral genes, which results in reduced transgene expression in transduced cells (25).

\section{The third-generation adenoviral vector: gutless adenovirus (GLAd)}

Despite the deletion of early transcriptional units (E1-E4), the early-generation adenoviral vectors still exhibit strong immunogenicity and toxicity in host organisms. These undesirable safety issues led to the development of the third-generation adenoviral vector, referred to as gutless adenovirus (GLAd). GLAd is constructed by deleting all the viral genes from an adenovirus, only leaving the ITRs and the $\psi$ packaging signal in its genome backbone (Fig. 2). This structural characteristic eliminates the expression of viral proteins in transduced cells and only induces negligible immune responses, enabling highlevel and persistent transgene expression in host organisms (26). Importantly, this large deletion also increases the cargo capacity for the transgene up to $36 \mathrm{~kb}$, which allows the delivery of a large transgene or multiple transgenes.

In general, most therapeutic transgenes do not reach $36 \mathrm{~kb}$. Therefore, the deleted viral genes should be replaced with a stuffer DNA to stably maintain the genome of GLAd within the size range (27-37.8 kb) for efficient encapsidation (27-29). The nature of stuffer DNA in GLAds appears to affect the expression of transgenes in vitro and in vivo. Parks et al. (30) showed that the GLAd containing a eukaryotic stuffer DNA leads to enhanced and persistent transgene expression compared with a similar vector containing a prokaryotic stuffer DNA. In contrast, Schiedner et al. (31) demonstrated that the origin of the stuffer DNA does not affect the transgene expression. Regardless of this controversy, the candidate for stuffer DNA must be carefully selected to avoid coding sequences, repetitive sequences, recombination sites, and immunogenic se- 
quences. Notably, the inclusion of a scaffold/matrix attachment region (S/MAR) (32) into the stuffer DNA can stabilize the genome of GLAd as an episome in the host cell nucleus.

Since GLAd is devoid of all the viral genes, its production requires a helper that supplies the viral proteins in trans, and thus, the GLAd is also called 'helper-dependent adenovirus (HDAd)'. Currently, the most commonly used helper is an adenovirus (33-35) that is usually an E1-deleted FGAd. Recombinant GLAd can be generated by co-infection (or co-transfection) of helper adenovirus (or helper adenoviral genome) and GLAd (or GLAd genome) into the packaging cell lines, such as HEK293 and HEK293T (Fig. 3A). This helper adeno-
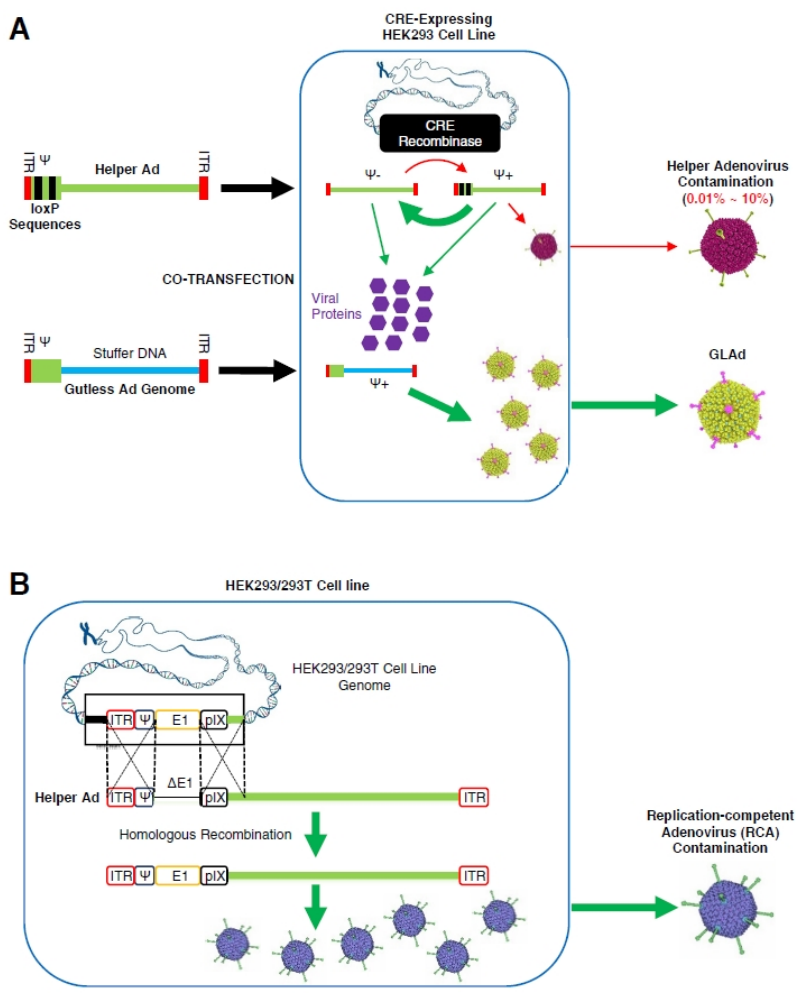

Fig. 3. Helper virus-dependent production of GLAd and the generation of RCA in the final product. (A) Helper virus-dependent production of GLAd using the Cre/loxP system. Genomes of GLAd and helper adenovirus are co-transfected into packaging cells, Cre recombinase-expressing HEK293 cell line, in which both viruses are amplified and the helper adenovirus produces viral proteins. During this process, the $\psi$ packaging signal flanked by loxP sites is excised by Cre recombinase, preventing the packaging of helper adenovirus genome, while the GLAd genome is packaged. The helper adenovirus contamination in the production of GLAd ranges from $0.01 \%$ to $10 \%$. (B) The generation of RCA. Two homologous sites are identified in the genomes of E1-deleted helper adenoviruses and E1-expressing packaging cells. Homologous recombination can occur in these two homologous regions, resulting in the generation of RCA as the helper adenovirus acquires the E1 region from the packaging cells. virus, which can replicate in the packaging cell lines, robustly supplies viral proteins. Unfortunately, however, helper adenovirus can remain as an undesirable contaminant in the final GLAd product (Fig. 3A). Furthermore, the helper adenovirus can be converted into RCA via homologous recombination between identical sequences present in the genomes of helper adenovirus and packaging cell lines (33) (Fig. 3B), which is similar to RCA generation in the FGAd production (16).

The helper adenovirus and RCA contaminants are hazardous, especially to the immunocompromised patients because the adenoviral proteins expressed by these two contaminant viruses can induce toxic immune responses. Besides, the strong host immune responses against helper adenovirus and RCA contaminants can limit the expression of the therapeutic transgene delivered by GLAd, even though GLAd per se induces negligible immune responses.

Indeed, the advantages of GLAd as a gene delivery vector are enormous. However, the safety concerns raised by the helper adenovirus and RCA contaminants have hindered its clinical applications. Accordingly, no clinical data are available for GLAd. Therefore, any clinical application requires the elimination of these two contaminants from the final preparation of GLAd.

To date, the most elegant strategy to prevent helper adenovirus amplification entails the deletion of the $\psi$ packaging signal (33). In this strategy, the $\psi$ packaging signal flanked by two loxP sites is excised when the helper adenovirus infects Cre-recombinase-expressing cell lines, such as 293Cre (Fig. $3 \mathrm{~A})$. The amplification of helper adenovirus is significantly reduced $(0.01-10 \%$ of total virus produced) by blocking the encapsidation of helper adenoviral genome. Based upon this Cre/LoxP production system, Palmer et al. (34) developed a method for large-scale production of GLAd, with a yield exceeding $1 \times 10^{12}$ blue forming units (BFU), and helper adenovirus contamination of $0.01 \%-0.02 \%$ following purification by a two-step $\mathrm{CsCl}$ gradient ultracentrifugation (36). However, despite the dramatic reduction, the contamination of helper adenovirus was unpreventable even with this sophisticated production system.

A similar strategy utilizing the FLP/frt system was also developed (37). However, it was still very difficult to completely remove the contaminated helper adenovirus.

In an attempt to address the safety concerns associated with helper adenovirus contamination, researchers have developed other strategies utilizing non-adenoviral helpers, such as baculovirus-adenovirus hybrid (38) and herpes simplex virus-1 (HSV-1) (39). Unfortunately, however, these two helpers also generated undesirable RCA contaminants and were shown to be inefficient in the production of GLAd.

Taken together, it is clear that the presence of helper viruses in the GLAd production system is an unavoidable risk. Therefore, establishing a system devoid of any helper viruses is of utmost importance for the production of GLAd that is desirable for clinical applications. 


\section{Helper virus-free gutless adenovirus (HF-GLAd)}

To address the aforementioned safety issues of GLAd, we developed helper virus-free gutless adenovirus (HF-GLAd), a new version of GLAd, which is produced in a helper virus-free manner (40). In this novel system, the helper function required for the HF-GLAd production is provided by a helper plasmid instead of a helper adenovirus. This helper plasmid does not contain the ITRs and the $\psi$ packaging signal, both of which are essential for viral genome replication and packaging. Therefore, this helper plasmid exclusively supplies viral proteins in trans, but cannot be converted into active adenovirus particles (Fig. $4 \mathrm{~A})$. Moreover, compared with the helper adenovirus, this helper plasmid contains only a single region for homologous recombination, which prevents conversion of this plasmid to RCA in the packaging cell lines, such as HEK293T (Fig. 4B).

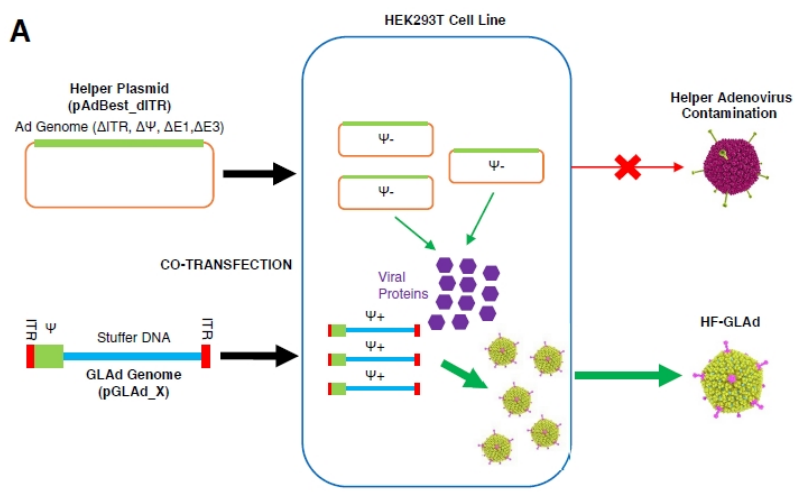

B

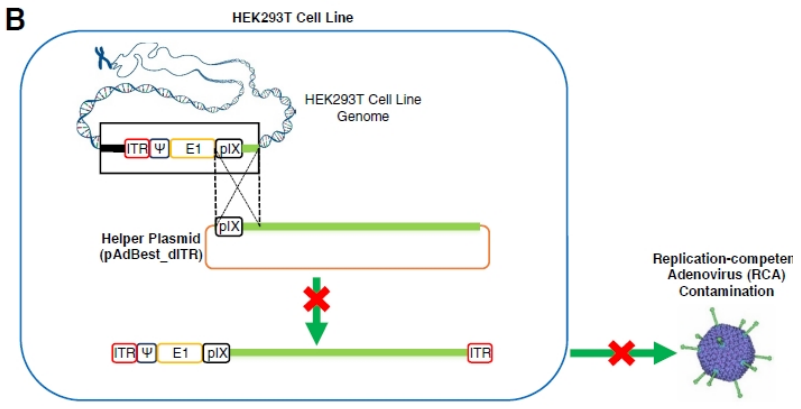

Fig. 4. Production of HF-GLAd with no RCA generation in the final product. (A) Production of HF-GLAd. GLAd genome (pGLAd_X) and helper plasmid (pAdBest_dITR) are co-transfected into a packaging cell line, HEK293T, in which the helper plasmid produces viral proteins for packaging of the GLAd genome. The helper plasmid cannot be amplified or packaged into the active viral particles, resulting in the production of HF-GLAd free of helper adenovirus. (B) No RCA generation during HF-GLAd production. Only one homologous recombination site is identified in the helper plasmid and E1-expressing packaging cells. Helper plasmid cannot acquire the E1 region from the genome of packaging cells via homologous recombination, which eliminates RCA generation in HFGLAd production.
Most importantly, this helper virus-free production system successfully produced large quantities of HF-GLAd free of helper adenovirus and RCA contaminants (40).

Briefly, the production of HF-GLAd requires two plasmids (Fig. 4A): (1) pAdBest_dITR ( $31 \mathrm{~kb})$, a helper plasmid that provides adenoviral proteins in trans; (2) pGLAd X (' $X$ ' stands for the gene of interest), a GLAd genome plasmid, part of which is packaged into the active viral particles. HF-GLAd can be generated by co-transfection of the helper plasmid and the linearized GLAd genome plasmid into the HEK293T packaging cells (Fig. 4A). Besides, an auxiliary plasmid, the pAd5pTP, is included to overexpress the precursor terminal protein (pTP) of HAd5 in HEK293T cells for increasing the yield of HF-GLAd (41).

In an attempt to produce large-scale HF-GLAd, a serial amplification process was established (40). This procedure is similar to the standard amplification process used for the helper adenovirus-dependent large-scale GLAd production (34). However, the packaging cells are transfected with helper plasmid in each round of amplification (40) instead of being infected with helper adenovirus (34). This serial amplification method (P0-P3) routinely achieved large-scale production of HF-GLAd with a yield of $5 \times 10^{10}-1 \times 10^{11}$ infectious units (ifu) (50-100 ifu/cell) in P3 (40). This yield is merely 10- to 20 -fold lower than that of the helper virus-dependent method (34), indicating that the helper plasmid supplies a sufficient amount of viral proteins for HF-GLAd production, although it cannot replicate in the packaging cells.

Since the selection of stuffer DNA is pivotal for sustaining high-level and persistent expression of transgenes, we selected fragments from the second intron of the mouse E-cadherin gene (42) as a stuffer DNA, which do not encode any proteins or carry homologous recombination sites. Additionally, we added an S/MAR element (43) to this stuffer DNA to stabilize it as an episome in the cell nucleus and also to increase the transgene expression.

We have successfully established a two-column chromatographic purification method to obtain highly pure recombinant HF-GLAd for preclinical and clinical applications. We are also investigating the possible adaptation of the culture dish-based serial amplification method (40) to the multi-layer Cell Factorybased (44) approach for large-scale production of HF-GLAd.

\section{ADENOVIRAL VECTOR-ASSOCIATED IMMUNE RESPONSES}

Viral vectors are the optimal gene therapy platforms because viruses have evolved to deliver their genetic material into permissive cells of other organisms. In parallel, the immune system of the host organism has also evolved to resist invasion of viral pathogens. An immune response against viral pathogens may benefit the application of vaccines (45-50) or anti-cancer therapy (51-53). However, an immune response against viral vectors used in gene therapy can eliminate the vectors and the 
transduced host cells. Such phenomena interfere with highlevel and persistent expression of therapeutic transgenes in host organisms. Therefore, circumventing the host immune responses against viral vectors is critical for the success of in vivo gene therapy.

The immune responses against adenoviral vector-based gene therapy can be summarized into two main classes: a rapid and non-specific innate immune response, and a relatively slow but highly specific adaptive immune response.

\section{Innate immune responses against adenovirus: the prologue} The adenovirus-mediated host innate immune responses induced by virion components (i.e., viral capsid proteins and DNA genome) are dose-dependent (54), and lead to upregulation of inflammatory gene expression (i.e., type I interferons) and cytokine secretion. These type I interferons and cytokines recruit immune cells to the administration sites (55-57), resulting in a rapid clearance of $80-90 \%$ vectors from the blood circulation and transduced tissues (58).

\section{Adaptive immune responses against adenoviral vectors: climax}

The adaptive immune responses induced by adenoviral vectors or adenovirus-based gene therapy are activated within a week (59). These immune responses can be elicited by the viral proteins expressed from the adenoviral vectors, or the products expressed by the therapeutic transgenes.

The viral proteins expressed by the early-generation adenoviral vectors induce cellular immune responses. In the early phase, the cytokines and chemokines are upregulated, leading to the infiltration of CD4 + and CD8 + T lymphocytes to the administration site of adenoviral vectors (60) and the generation of adenovirus-specific cytotoxic T lymphocytes (CTLs) (61). These cellular immune responses are initiated by antigen-presenting cells (APCs), resulting in the elimination of transduced host cells and the generation of memory immune cells against the adenoviral vectors (62).

Administration of adenoviral vectors also induces humoral adaptive immune responses via presentation of MHC-II/adenoviral capsid antigen complexes at the surface of B lymphocytes to $\mathrm{CD} 4+\mathrm{T}$ lymphocytes, which results in the activation of CD4 + T lymphocytes. Following the activation, CD4 + Th2 lymphocytes promote the proliferation of B lymphocytes and their differentiation to plasma cells that secrete antibodies against adenoviral capsid proteins. The pre-existing neutralizing antibodies (NAbs) in host organisms (63) may interfere with adenovirus infection and thereby decrease the efficacy of adenoviral vector-based gene therapy (64-66).

The products encoded by therapeutic transgenes may also be immunogenic in patients with null mutations. These products may be presented by APCs to CD4 + and CD8 + T lymphocytes and recognized as neo-antigens by the host immune system (67). From a therapeutic point of view, it is expected that repeated administration of gene delivery vector is required to maintain a sustained expression of therapeutic transgenes in tissues or organs with a high regeneration rate (i.e., respiratory and gastrointestinal epithelium). The repeated administration of gene delivery vectors or sustained expression of therapeutic transgenes acts as a 'prime-boost vaccination', which decreases the duration of therapeutic transgene expression and the efficacy of gene therapy.

\section{Immune responses against HF-GLAd}

GLAd is devoid of all the viral genes. Thus, GLAd does not express any adenoviral proteins in transduced host cells, which minimizes the induction of adenovirus-specific adaptive immune responses, enabling high-level and persistent transgene expression in host organisms. Importantly, as HF-GLAd is produced in the absence of helper adenovirus, its final product is free of helper adenovirus and RCA contaminants. Therefore, HF-GLAd is clinically more desirable than the GLAd produced by the helper adenovirus-dependent system.

Nevertheless, HF-GLAd can still induce innate immune responses, since it shares an identical capsid structure with wild-type and early-generation adenoviruses (68). Also, pre-existing NAbs and/or adenovirus-specific CTLs present in the patients previously exposed to adenoviruses can decrease the efficacy of HF-GLAd-based gene therapy (63).

\section{Strategies to circumvent immune responses against HF-GLAd} Several elegant strategies have been developed to circumvent the host immune responses against adenoviral vectors. These strategies include transient immune modulation in the host organism before administrating these vectors, and selective modification of these vectors per se.

Transient immune modulation entails either pre-deletion of immune cells or induction of immunosuppression (or immune tolerance). For example, transient depletion of specific immune cells (i.e., CD4 + and CD8 + T lymphocytes, B lymphocytes, and NK cells) by injecting antibodies can significantly increase the transduction and re-administration efficiency of GLAd in mouse liver (69). Transient treatment with immunosuppressants or agents inducing immune tolerance, such as glucocorticoids, FK506, dexamethasone, cyclosporin A, cyclophosphamide, mCTLA4-Ig, or mycophenolate mofetil, has been shown to increase the levels and duration of GLAd-mediated transgene expression in various animal models (70-73).

As an approach for selective modification, adenoviral capsid proteins can be conjugated with chemicals, such as polyethylene glycol (PEG) $(74,75)$. The adenoviral vectors containing such modified capsid proteins have already been shown to improve the vector safety and transduction efficiency. Therefore, these approaches, individually or in combination, can also be adopted in HF-GLAd-based gene therapy.

Several other strategies were also investigated to minimize adenovirus-mediated host immune responses. For example, since host innate immune responses against adenoviral vectors are dose-dependent, it is crucial to establish a threshold dose 
to minimize the acute toxic immune responses. Also, it is preferable to select immune-privileged tissues or organs, especially the eye and central nervous system (CNS), as in vivo administration targets, given their significantly low immune responses against foreign antigens $(76,77)$. Therefore, the eye and CNS are ideal targets for HF-GLAd-based gene therapy, owing to their immune-privileged characteristics and the need for relatively low vector doses to achieve sufficient therapeutic efficacy (78).

\section{HF-GLAD AS A GENE DELIVERY VECTOR FOR IN VIVO GENE THERAPY}

Recombinant adenoviral vectors have been extensively investigated in preclinical and clinical applications. However, the tragic death of Jesse Gelsinger, who was treated for ornithine transcarbamoylase (OTC) deficiency, has severely damaged the reputation of adenovirus-based gene therapy (79). Although these vectors have shown tremendous advantages and technological advances (i.e., the advent of GLAd), safety concerns have led to a significant decline in their clinical applications for inherited genetic diseases. Since then, the majority of in vivo gene delivery has shifted to the vectors with less immunogenicity and toxicity. As a result, adenoassociated viruses (AAVs) have become mainstream in development of gene therapy $(80,81)$, and three AAV-based gene therapy drugs have been approved (4-6). Similar to GLAd, the AAVs are also 'gutless'; however, AAVs carry a small cargo $(\sim 4.5 \mathrm{~kb})$ appropriate for only small transgenes (Table 1$)$, which poses an undeniable limitation in large transgene delivery. Therefore, the focus of AAV-based gene therapy applications is on the delivery of small or truncated transgenes, such as the SMN1 gene $(\sim 1.5 \mathrm{~kb}$, a target for spinal muscular atrophy) (82), the FIX gene ( $\sim 2.8 \mathrm{~kb}$, a target for hemophilia B) (83), the RPE65 gene $(\sim 2.6 \mathrm{~kb}$, a target for Leber's congenital amaurosis 2) (84), and the micro-DMD gene $(\sim 4.2 \mathrm{~kb}$, a target for Duchenne and Becker muscular dystrophy) (85).

Gene therapy using GLAd has attracted tremendous attention in recent years. In particular, in addition to a substantial capacity for transgenes (Table 1), the safety of HF-GLAd is comparable to that of AAV, which is expected to restore the reputation of adenoviral vectors as well as facilitate its applications for in vivo gene therapy. Although the HF-GLAd remains to be clinically evaluated, it has already shown high efficiency in in vitro and in vivo gene delivery (40).

HF-GLAd is capable of delivering transgenes regardless of size because no human gene exceeds its carrying capacity. HF-GLAd can accommodate a small or a large transgene, and even multiple transgenes in a single construct. In theory, HF-GLAd might be an ideal vector to safely deliver large transgenes to treat inherited genetic diseases, such as Duchenne and Becker muscular dystrophy (with mutations in the DMD gene, $\sim 11 \mathrm{~kb})(40,86-88)$, Huntington's disease (with muta-
Table 1. Comparison of helper virus-dependent GLAd, HF-GLAd, and AAV

\begin{tabular}{|c|c|c|c|}
\hline & $\begin{array}{c}\text { Helper } \\
\text { virus-depen- } \\
\text { dent GLAd }\end{array}$ & HF-GLAd & $\mathrm{AAV}^{\mathrm{a}}$ \\
\hline $\begin{array}{l}\text { Use of helper adenovirus in } \\
\text { production }\end{array}$ & YES & $\mathrm{NO}$ & $n / a^{d}$ \\
\hline $\begin{array}{l}\text { Use of helper plasmid in } \\
\text { production }\end{array}$ & $n / a^{d}$ & YES & $n / a^{d}$ \\
\hline $\begin{array}{l}\text { Helper adenovirus } \\
\text { contamination }\end{array}$ & YES & NO & $n / a^{d}$ \\
\hline $\mathrm{RCA}^{\mathrm{b}}$ contamination & YES & NO & $n / a^{d}$ \\
\hline $\begin{array}{l}\text { Cargo capacity for } \\
\text { transgenes }\end{array}$ & $\sim 36 \mathrm{~kb}$ & $\sim 36 \mathrm{~kb}$ & $\sim 4.5 \mathrm{~kb}$ \\
\hline Efficiency ${ }^{c}$ of transduction & $100 \%$ & $100 \%$ & $40 \%$ \\
\hline Broad tropism & YES & YES & YES \\
\hline $\begin{array}{l}\text { Random integration into } \\
\text { host genome } \\
\text { (potential of } \\
\text { insertional mutagenesis) }\end{array}$ & NO & NO & $\mathrm{YES}^{\mathrm{e}}$ \\
\hline Expression of viral proteins & NO & NO & $\mathrm{NO}$ \\
\hline $\begin{array}{l}\text { In vivo acute toxicity by } \\
\text { viral capsid }\end{array}$ & YES & YES & YES \\
\hline In vivo chronic toxicity & NO & NO & $\mathrm{NO}$ \\
\hline $\begin{array}{l}\text { Long-term in vivo } \\
\text { transgene expression }\end{array}$ & YES & YES & YES \\
\hline
\end{tabular}

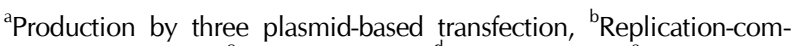
petent adenovirus, ${ }^{\mathrm{c}}$ Relative activity, ${ }^{\mathrm{d}}$ Not applicable, ${ }^{\mathrm{e}}$ Although frequency is low.

tions involving the HTT gene, $\sim 9.4 \mathrm{~kb})(40,89)$, Leber's congenital amaurosis 10 (associated with CEP290 gene mutations, $\sim 7.5 \mathrm{~kb}$ ) (90), Stargardt disease type I (associated with ABCA4 gene mutations, $\sim 6.8 \mathrm{~kb}$ ) (91-93), retinitis pigmentosa 25 (with mutations involving the EYS gene, $\sim 9.5 \mathrm{~kb})(94)$, and retinitis pigmentosa 39 (associated with USH2A gene mutations, 15.6 kb) (95). We have successfully constructed the recombinant HF-GLAds harboring codon-optimized transgene for each of these diseases. Currently, the safety and efficacy of HF-GLAdbased gene therapies for the treatment of inherited genetic diseases are being evaluated under consideration of clinical applications.

\section{CONCLUSION AND FUTURE PERSPECTIVES}

GLAd is one of the most promising vectors for in vivo gene therapy, given its advantages. However, the safety concerns raised by undesirable helper adenovirus and RCA contaminants have hindered its clinical applications. Recently, we have successfully created HF-GLAd as a new platform for gene therapy, which is devoid of helper adenovirus and RCA contaminants. This revolutionary advance will facilitate clinical applications of the HF-GLAd.

Currently, many recombinant HF-GLAds are under investiga- 
tion in animal studies for the treatment of various inherited genetic diseases. Further, HF-GLAd also carries the potential for delivery of therapeutic transgenes to treat other diseases, such as Parkinson's disease (96, 97), Alzheimer's disease (98), and cancer (in situ vaccination) (99). We sincerely hope that the application of HF-GLAd will unlock the full potential of gene therapy and open new vistas in the treatment of a much broader spectrum of diseases.

\section{ACKNOWLEDGEMENTS}

This research was supported by the Chung-Ang University Young Scientist Scholarship in 2014. We thank Christine Seol for critical reading of the manuscript.

\section{CONFLICTS OF INTEREST}

The authors have no conflicting interests.

\section{REFERENCES}

1. Blaese RM, Culver KW, Miller AD et al (1995) T lymphocyte-directed gene therapy for ADA- SCID: initial trial results after 4 years. Science $270,475-480$

2. Bordignon C, Notarangelo LD, Nobili N et al (1995) Gene therapy in peripheral blood lymphocytes and bone marrow for ADA- immunodeficient patients. Science 270, 470-475

3. Kohn DB, Weinberg KI, Nolta JA et al (1995) Engraftment of gene-modified umbilical cord blood cells in neonates with adenosine deaminase deficiency. Nat Med 1, 1017-1023

4. Yla-Herttuala S (2012) Endgame: glybera finally recommended for approval as the first gene therapy drug in the European union. Mol Ther 20, 1831-1832

5. Darrow JJ (2019) Luxturna: FDA documents reveal the value of a costly gene therapy. Drug Discov Today 24, 949-954

6. Mahajan R (2019) Onasemnogene abeparvovec for spinal muscular atrophy: the costlier drug ever. Int J Appl Basic Med Res 9, 127-128

7. Lee CS, Bishop ES, Zhang R et al (2017) Adenovirusmediated gene delivery: potential applications for gene and cell-based therapies in the new era of personalized medicine. Genes Dis 4, 43-63

8. Rowe WP, Huebner RJ, Gilmore LK, Parrott RH and Ward TG (1953) Isolation of a cytopathogenic agent from human adenoids undergoing spontaneous degeneration in tissue culture. Proc Soc Exp Biol Med 84, 570-573

9. Hilleman MR and Werner JH (1954) Recovery of new agent from patients with acute respiratory illness. Proc Soc Exp Biol Med 85, 183-188

10. Crystal RG (2014) Adenovirus: the first effective in vivo gene delivery vector. Hum Gene Ther 25, 3-11

11. Gaynor RB and Berk AJ (1983) Cis-acting induction of adenovirus transcription. Cell 33, 683-693

12. Lichtenstein $\mathrm{DL}$, Toth $\mathrm{K}$, Doronin $\mathrm{K}$, Tollefson $\mathrm{AE}$ and Wold WS (2004) Functions and mechanisms of action of the adenovirus E3 proteins. Int Rev Immunol 23, 75-111

13. Graham FL, Smiley J, Russell WC and Nairn R (1977) Characteristics of a human cell line transformed by DNA from human adenovirus type 5. J Gen Virol 36, 59-74

14. Louis N, Evelegh C and Graham FL (1997) Cloning and sequencing of the cellular-viral junctions from the human adenovirus type 5 transformed 293 cell line. Virology 233, 423-429

15. Murakami P, Pungor E, Files J et al (2002) A single short stretch of homology between adenoviral vector and packaging cell line can give rise to cytopathic effect-inducing, helper-dependent E1-positive particles. Hum Gene Ther 13, 909-920

16. Lochmuller H, Jani A, Huard J et al (1994) Emergence of early region 1-containing replication-competent adenovirus in stocks of replication-defective adenovirus recombinants (delta E1 + delta E3) during multiple passages in 293 cells. Hum Gene Ther 5, 1485-1491

17. Smith JG and Eck SL (1999) Molecular characterization of an adenoviral vector resulting from both homologous and nonhomologous recombination. Cancer Gene Ther 6, 475-481

18. Simek S, Byrnes A, Bauer S (2002) FDA Perspectives on the use of the adenovirus reference material. BioProcess J $1,40-42$

19. Fallaux FJ, Bout A, van der Velde I et al (1998) New helper cells and matched early region 1-deleted adenovirus vectors prevent generation of replication-competent adenoviruses. Hum Gene Ther 9, 1909-1917

20. Imperiale MJ, Kao HT, Feldman LT, Nevins JR and Strickland S (1984) Common control of the heat shock gene and early adenovirus genes: evidence for a cellular E1A-like activity. Mol Cell Biol 4, 867-874

21. Lozier JN, Csako G, Mondoro TH et al (2002) Toxicity of a first-generation adenoviral vector in rhesus macaques. Hum Gene Ther 13, 113-124

22. Jiang H, Rivera-Molina Y, Gomez-Manzano C et al (2017) Oncolytic adenovirus and tumor-targeting immune modulatory therapy improve autologous cancer vaccination. Cancer Res 77, 3894-3907

23. Swaminathan S and Thimmapaya B (1995) Regulation of adenovirus E2 transcription unit; in the molecular repertoire of adenoviruses III: biology and pathogenesis, Doerfler W and Böhm P (eds.), 177-194, Springer Berlin Heidelberg, Berlin, Heidelberg

24. Evans JD and Hearing P (2003) Distinct roles of the adenovirus E4 ORF3 protein in viral DNA replication and inhibition of genome concatenation. J Virol 77, 5295-5304

25. O'Neal WK, Zhou H, Morral N et al (1998) Toxicological comparison of E2a-deleted and first-generation adenoviral vectors expressing alpha1-antitrypsin after systemic delivery. Hum Gene Ther 9, 1587-1598

26. Jozkowicz A, Dulak J, Nanobashvili J, Polterauer P, Prager M and Huk I (2002) Gutless adenoviral vectors - promising tools for gene therapy. European Surgery-Acta Chirurgica Austriaca 34, 95-100

27. Bett AJ, Prevec L and Graham FL (1993) Packaging capacity and stability of human adenovirus type 5 vectors. J Virol 67, 5911-5921

28. Alemany R, Dai Y, Lou YC et al (1997) Complementation 
of helper-dependent adenoviral vectors: size effects and titer fluctuations. J Virol Methods 68, 147-159

29. Parks RJ and Graham FL (1997) A helper-dependent system for adenovirus vector production helps define a lower limit for efficient DNA packaging. J Virol 71, 32933298

30. Parks RJ, Bramson JL, Wan Y, Addison CL and Graham FL (1999) Effects of stuffer DNA on transgene expression from helper-dependent adenovirus vectors. J Virol 73, 8027-8034

31. Schiedner G, Hertel S, Johnston M, Biermann V, Dries V and Kochanek S (2002) Variables affecting in vivo performance of high-capacity adenovirus vectors. J Virol 76, 1600-1609

32. Sandig V, Youil R, Bett AJ et al (2000) Optimization of the helper-dependent adenovirus system for production and potency in vivo. Proc Natl Acad Sci U S A 97, 1002-1007

33. Parks RJ, Chen L, Anton M, Sankar U, Rudnicki MA and Graham FL (1996) A helper-dependent adenovirus vector system: removal of helper virus by Cre-mediated excision of the viral packaging signal. Proc Natl Acad Sci U S A 93, 13565-13570

34. Palmer D and Ng P (2003) Improved system for helperdependent adenoviral vector production. Mol Ther 8, 846-852

35. Jager L, Hausl MA, Rauschhuber C, Wolf NM, Kay MA and Ehrhardt A (2009) A rapid protocol for construction and production of high-capacity adenoviral vectors. Nat Protoc 4, 547-564

36. Su Q, Sena-Esteves M and Gao G (2019) Purification of the recombinant adenovirus by cesium chloride gradient centrifugation. Cold Spring Harb Protoc 2019, pdb.prot 095547

37. Ng P, Beauchamp C, Evelegh C, Parks R and Graham FL (2001) Development of a FLP/frt system for generating helper-dependent adenoviral vectors. Mol Ther 3, 809-815

38. Cheshenko N, Krougliak N, Eisensmith RC and Krougliak VA (2001) A novel system for the production of fully deleted adenovirus vectors that does not require helper adenovirus. Gene Ther 8, 846-854

39. Kubo S, Saeki Y, Chiocca EA and Mitani K (2003) An HSV amplicon-based helper system for helper-dependent adenoviral vectors. Biochem Biophys Res Commun 307, 826-830

40. Lee D, Liu J, Junn HJ, Lee EJ, Jeong KS and Seol DW (2019) No more helper adenovirus: production of gutless adenovirus (GLAd) free of adenovirus and replication-competent adenovirus (RCA) contaminants. Exp Mol Med 51, $1-18$

41. Wu N, Zhang H, Deng F et al (2014) Overexpression of Ad5 precursor terminal protein accelerates recombinant adenovirus packaging and amplification in HEK-293 packaging cells. Gene Ther 21, 629-637

42. Stemmler MP, Hecht A and Kemler R (2005) E-cadherin intron 2 contains cis-regulatory elements essential for gene expression. Development 132, 965-976

43. Harraghy N, Gaussin A and Mermod N (2008) Sustained transgene expression using MAR elements. Curr Gene Ther 8, 353-366

44. Suzuki M, Cela R, Clarke C, Bertin TK, Mourino S and Lee B (2010) Large-scale production of high-quality helperdependent adenoviral vectors using adherent cells in cell factories. Hum Gene Ther 21, 120-126

45. Smaill F, Jeyanathan M, Smieja M et al (2013) A human type 5 adenovirus-based tuberculosis vaccine induces robust T cell responses in humans despite preexisting anti-adenovirus immunity. Sci Transl Med 5, 205ra134

46. McElrath MJ, De Rosa SC, Moodie Z et al (2008) HIV-1 vaccine-induced immunity in the test-of-concept Step Study: a case-cohort analysis. Lancet 372, 1894-1905

47. Harro C, Sun X, Stek JE et al (2009) Safety and immunogenicity of the Merck adenovirus serotype 5 (MRKAd5) and MRKAd6 human immunodeficiency virus type 1 trigene vaccines alone and in combination in healthy adults. Clin Vaccine Immunol 16, 1285-1292

48. Mennechet FJ, Tran TT, Eichholz K, van de Perre P and Kremer EJ (2015) Ebola virus vaccine: benefit and risks of adenovirus-based vectors. Expert Rev Vaccines 14, 1471-1478

49. Green CA, Scarselli E, Sande CJ et al (2015) Chimpanzee adenovirus- and MVA-vectored respiratory syncytial virus vaccine is safe and immunogenic in adults. Sci Transl Med 7, 300ra126

50. Scallan CD, Tingley DW, Lindbloom JD, Toomey JS and Tucker SN (2013) An adenovirus-based vaccine with a double-stranded RNA adjuvant protects mice and ferrets against $\mathrm{H} 5 \mathrm{~N} 1$ avian influenza in oral delivery models. Clin Vaccine Immunol 20, 85-94

51. Alemany R (2014) Oncolytic adenoviruses in cancer treatment. Biomedicines 2, 36-49

52. Huang H, Liu Y, Liao W et al (2019) Oncolytic adenovirus programmed by synthetic gene circuit for cancer immunotherapy. Nat Commun 10, 4801

53. Yamamoto $M$ and Curiel DT (2010) Current issues and future directions of oncolytic adenoviruses. Mol Ther 18, 243-250

54. Brunetti-Pierri N, Palmer DJ, Beaudet AL, Carey KD, Finegold M and Ng P (2004) Acute toxicity after high-dose systemic injection of helper-dependent adenoviral vectors into nonhuman primates. Hum Gene Ther 15, 35-46

55. Schnell MA, Zhang Y, Tazelaar J et al (2001) Activation of innate immunity in nonhuman primates following intraportal administration of adenoviral vectors. Mol Ther 3, 708722

56. Basner-Tschakarjan E, Gaffal E, O'Keeffe M et al (2006) Adenovirus efficiently transduces plasmacytoid dendritic cells resulting in TLR9-dependent maturation and IFN-alpha production. J Gene Med 8, 1300-1306

57. Hartman ZC, Kiang A, Everett RS et al (2007) Adenovirus infection triggers a rapid, MyD88-regulated transcriptome response critical to acute-phase and adaptive immune responses in vivo. J Virol 81, 1796-1812

58. Worgall S, Wolff G, Falck-Pedersen E and Crystal RG (1997) Innate immune mechanisms dominate elimination of adenoviral vectors following in vivo administration. Hum Gene Ther 8, 37-44

59. Xiang ZQ, Yang Y, Wilson JM and Ertl HC (1996) A replication-defective human adenovirus recombinant serves as a highly efficacious vaccine carrier. Virology $219,220-227$

60. Kafri T, Morgan D, Krahl T, Sarvetnick N, Sherman L and Verma I (1998) Cellular immune response to adenoviral vector infected cells does not require de novo viral gene 
expression: implications for gene therapy. Proc Natl Acad Sci U S A 95, 11377-11382

61. Molinier-Frenkel V, Gahery-Segard $H$, Mehtali $M$ et al (2000) Immune response to recombinant adenovirus in humans: capsid components from viral input are targets for vector-specific cytotoxic T lymphocytes. J Virol 74, 7678-7682

62. Zhong L, Granelli-Piperno A, Choi $Y$ and Steinman RM (1999) Recombinant adenovirus is an efficient and non-perturbing genetic vector for human dendritic cells. European Journal of Immunology 29, 964-972

63. Fausther-Bovendo $\mathrm{H}$ and Kobinger GP (2014) Pre-existing immunity against Ad vectors: humoral, cellular, and innate response, what's important? Hum Vaccin Immunother 10, 2875-2884

64. Smith JG, Cassany A, Gerace L, Ralston R and Nemerow GR (2008) Neutralizing antibody blocks adenovirus infection by arresting microtubule-dependent cytoplasmic transport. J Virol 82, 6492-6500

65. Parker AL, Waddington SN, Buckley SM et al (2009) Effect of neutralizing sera on factor $x$-mediated adenovirus serotype 5 gene transfer. J Virol 83, 479-483

66. Pichla-Gollon SL, Lin SW, Hensley SE et al (2009) Effect of preexisting immunity on an adenovirus vaccine vector: in vitro neutralization assays fail to predict inhibition by antiviral antibody in vivo. J Virol 83, 5567-5573

67. Calcedo R, Somanathan S, Qin Q et al (2017) Class I-restricted T-cell responses to a polymorphic peptide in a gene therapy clinical trial for alpha-1-antitrypsin deficiency. Proc Natl Acad Sci U S A 114, 1655-1659

68. Muruve DA, Cotter MJ, Zaiss AK et al (2004) Helperdependent adenovirus vectors elicit intact innate but attenuated adaptive host immune responses in vivo. J Virol 78, 5966-5972

69. Alzuguren P, Hervas-Stubbs S, Gonzalez-Aseguinolaza G et al (2015) Transient depletion of specific immune cell populations to improve adenovirus-mediated transgene expression in the liver. Liver Int 35, 1274-1289

70. Dai Y, Schwarz EM, Gu D, Zhang WW, Sarvetnick N and Verma IM (1995) Cellular and humoral immune responses to adenoviral vectors containing factor IX gene: tolerization of factor IX and vector antigens allows for long-term expression. Proc Natl Acad Sci U S A 92, 1401-1405

71. Kaplan JM and Smith AE (1997) Transient immunosuppression with deoxyspergualin improves longevity of transgene expression and ability to readminister adenoviral vector to the mouse lung. Hum Gene Ther 8, 1095-1104

72. Otake K, Ennist DL, Harrod K and Trapnell BC (1998) Nonspecific inflammation inhibits adenovirus-mediated pulmonary gene transfer and expression independent of specific acquired immune responses. Hum Gene Ther 9, 2207-2222

73. Engelhardt JF, Simon RH, Yang Y et al (1993) Adenovirusmediated transfer of the CFTR gene to lung of nonhuman primates: biological efficacy study. Hum Gene Ther 4, 759-769

74. Chillon M, Lee JH, Fasbender A and Welsh MJ (1998) Adenovirus complexed with polyethylene glycol and cationic lipid is shielded from neutralizing antibodies in vitro. Gene Ther 5, 995-1002

75. Croyle MA, Chirmule N, Zhang Y and Wilson JM (2001) "Stealth" adenoviruses blunt cell-mediated and humoral immune responses against the virus and allow for significant gene expression upon readministration in the lung. J Virol 75, 4792-4801

76. Benhar I, London A and Schwartz M (2012) The privileged immunity of immune privileged organs: the case of the eye. Front Immunol 3, 296

77. Galea I, Bechmann I and Perry VH (2007) What is immune privilege (not)? Trends Immunol 28, 12-18

78. Alliegro $M$, Ferla $R$, Nusco E, De Leonibus C, Settembre $C$ and Auricchio A (2016) Low-dose gene therapy reduces the frequency of enzyme replacement therapy in a mouse model of lysosomal storage disease. Mol Ther 24, 20542063

79. Marshall E (1999) Gene therapy death prompts review of adenovirus vector. Science 286, 2244-2245

80. Naso MF, Tomkowicz B, Perry WL 3rd and Strohl WR (2017) Adeno-associated virus (AAV) as a vector for gene therapy. BioDrugs 31, 317-334

81. Wang D, Tai PWL and Gao G (2019) Adeno-associated virus vector as a platform for gene therapy delivery. Nat Rev Drug Discov 18, 358-378

82. Armbruster N, Lattanzi A, Jeavons M et al (2016) Efficacy and biodistribution analysis of intracerebroventricular administration of an optimized scAAV9-SMN1 vector in a mouse model of spinal muscular atrophy. Mol Ther Methods Clin Dev 3, 16060

83. George LA, Sullivan SK, Giermasz A et al (2017) Hemophilia B gene therapy with a high-specific-activity factor IX variant. N Engl J Med 377, 2215-2227

84. Pierce EA and Bennett J (2015) The status of RPE65 gene therapy trials: safety and efficacy. Cold Spring Harb Perspect Med 5, a017285

85. Duan D (2018) Systemic AAV micro-dystrophin gene therapy for duchenne muscular dystrophy. Mol Ther 26, 2337-2356

86. Kharraz Y, Guerra J, Pessina P, Serrano AL and MunozCanoves P (2014) Understanding the process of fibrosis in Duchenne muscular dystrophy. Biomed Res Int 2014, 965631

87. Dudley RW, Lu Y, Gilbert R et al (2004) Sustained improvement of muscle function one year after full-length dystrophin gene transfer into $\mathrm{mdx}$ mice by a gutted helper-dependent adenoviral vector. Hum Gene Ther 15, 145-156

88. Gilbert R, Nalbantoglu J, Howell JM et al (2001) Dystrophin expression in muscle following gene transfer with a fully deleted ("gutted") adenovirus is markedly improved by trans-acting adenoviral gene products. Hum Gene Ther 12, 1741-1755

89. Bates GP, Dorsey R, Gusella JF et al (2015) Huntington disease. Nat Rev Dis Primers 1, 15005

90. den Hollander AI, Koenekoop RK, Yzer S et al (2006) Mutations in the CEP290 (NPHP6) gene are a frequent cause of Leber congenital amaurosis. Am J Hum Genet 79, 556-561

91. Lee W, Xie Y, Zernant J et al (2016) Complex inheritance of ABCA4 disease: four mutations in a family with multi- 
ple macular phenotypes. Hum Genet 135, 9-19

92. Tsybovsky Y, Molday RS and Palczewski K (2010) The ATP-binding cassette transporter ABCA4: structural and functional properties and role in retinal disease. Adv Exp Med Biol 703, 105-125

93. Guse K, Sule G, He F et al (2012) 160. Gene therapy for stargardt disease using helper-dependent adenoviral vectors. Mol Ther 20, S64

94. McGuigan DB, Heon E, Cideciyan AV et al (2017) EYS mutations causing autosomal recessive retinitis pigmentosa: changes of retinal structure and function with disease progression. Genes (Basel) 8, 178

95. Pierrache LH, Hartel BP, van Wijk E et al (2016) Visual prognosis in $\mathrm{USH} 2 \mathrm{~A}$-associated retinitis pigmentosa is worse for patients with usher syndrome type iia than for those with nonsyndromic retinitis pigmentosa. Ophthalmology $123,1151-1160$

96. Sun $M$, Kong L, Wang X et al (2004) Coexpression of tyrosine hydroxylase, GTP cyclohydrolase I, aromatic amino acid decarboxylase, and vesicular monoamine transporter 2 from a helper virus-free herpes simplex virus type 1 vector supports high-level, long-term biochemical and behavioral correction of a rat model of Parkinson's disease. Hum Gene Ther 15, 1177-1196

97. Axelsen TM and Woldbye DPD (2018) Gene therapy for Parkinson's disease, an update. J Parkinsons Dis 8, 195215

98. Nilsson P, Iwata N, Muramatsu S, Tjernberg LO, Winblad B and Saido TC (2010) Gene therapy in Alzheimer's disease - potential for disease modification. J Cell Mol Med 14, 741-757

99. Hammerich L, Marron TU, Upadhyay R et al (2019) Systemic clinical tumor regressions and potentiation of PD1 blockade with in situ vaccination. Nat Med 25, 814824 